\title{
Immediate Breast Reconstruction vs. Mastectomy Alone in Locally Advanced Breast Cancer; Local Recurrence and Distant Recurrence
}

\author{
Youngjin Kim, M.D. ${ }^{1}$, Eun-Shin Lee, M.D., Ph.D. ${ }^{1}$, Jong Ho Cheun, M.D. ${ }^{1}$, Jigwang Jung, M.D. ${ }^{1}$, \\ Han-Byoel Lee, M.D., Ph.D. ${ }^{1,2}$, Hyeong-Gon Moon, M.D., Ph.D. ${ }^{1,2}$, Dong-Young Noh, M.D., Ph.D. ${ }^{1,3}$, \\ Wonshik Han, M.D., Ph.D. ${ }^{1,2,3}$ \\ ${ }^{1}$ Department of Surgery, Seoul National University College of Medicine, Seoul; ${ }^{2}$ Biomedical Research Institute, Seoul National University Hospital, \\ Seoul; ${ }^{3}$ Cancer Research Institute, Seoul National University, Seoul, Korea
}

Purpose: The oncologic safety of immediate breast reconstruction (IBR) has been demonstrated. However, the outcome of IBR for locally advanced breast cancer $(\mathrm{LABC})$ is still under debate. We compared the survival outcome of $L A B C$ patients who underwent IBR vs. mastectomy alone. Methods: We retrospectively analyzed a total of 248 patients with stage III breast cancer who were treated with mastectomy between 2004 and 2015. The study subjects were divided into 2 groups: patients who received IBR $(n=77)$ or mastectomy alone (MA) $(n=171)$. We compared disease-free survival (DFS) of both groups. Results: Median follow-up duration was 49 months and the mean age of patients was 49 years. Patients in the IBR group were significantly younger and had lower body mass index (BMI) than those in the MA group. In a univariate analysis, IBR group showed better DFS than the MA group (DFS 81.3 months vs. 49.8 months, $p<0.001$ ). There was no delay in adjuvant treatment in the IBR group. In a multivariate analysis, IBR was associated with better DFS (hazard ratio (HR) for recurrence: 0.37 , $95 \% \mathrm{Cl} 0.20-0.69, p=0.002$ ) when adjusted for potential prognostic factors. In a subgroup analysis performed according to disease stage (IIIA and IIIB/IIIC), DFS was significantly better in IBR than MA group in both stage subgroups $(p<0.001)$. Conclusion: We demonstrated that patients who underwent IBR showed better DFS outcome compared with patients who underwent mastectomy alone. Our results can help surgeons to determine if IBR is an option in patients with LABC.

Key Words: Breast neoplasms, Disease-free survival, Local neoplasm recurrence, Mammoplasty

\section{INTRODUCTION}

Recent advances in treatment modalities of breast cancer have led to significant improvement in patient outcomes. The quality of life for breast cancer survivors has become a more important issue. Patients who undergo mastectomy can suffer from impairment of body image, loss of sexual function, or emotional disturbances, which may negatively impact quality of life. Many studies have established that breast reconstruction performed at the time of mastectomy, termed IBR, can reduce psychosocial problems and improve quality of life. The improvement in both implant and autologous techniques, thus, providing better aesthetic results, has led to a rapid expansion of IBR over the past 2 decades [1-4]. Immediate reconstruction has been shown to be both feasible and oncological safe without any evidence of increased

Correspondence: Wonshik Han, M.D., Ph.D.

Department of Surgery, Seoul National University College of Medicine, 101 Daehak-ro, Jongno-gu, Seoul 03080, Korea

Tel: +82-2-2072-1958, Fax: +82-2-766-3975, E-mail: hanw@snu.ac.kr

Received: Aug 21, 2019 Revised: Oct 25, 2019 Accepted: Nov 6, 2019 mortality when compared with delayed reconstruction or mastectomy alone. However, relatively small series of patients with advanced stage cancer were involved in most studies of the relationship between breast reconstruction and survival outcomes, whereas large cohorts with early stage breast cancer were well evaluated [5-9]. Several reports have regarded patients with $\mathrm{LABC}$ as unfavorable candidates for IBR because of high recurrence rate and concerns about further exacerbated mortality caused by disturbance in detecting local relapse lesions and delays in postoperative therapy [10-16]. As current multi-modality treatments including chemotherapy, targeted therapy and post-mastectomy radiotherapy (PMRT) are essential to improve survival outcome in LABC, a possible delay in the delivery of adjuvant therapy due to IBR has become a matter of concern. This in turn may negatively affect recurrence and survival rates. There are some studies that demonstrated no statistically significant differences in survival outcomes between those underwent IBR vs. mastectomy alone. According to the study using the Surveillance, Epidemiology, and End Results (SEER) data, there are comparable survival outcomes in LABC patients who 
received immediate breast reconstruction or mastectomy alone followed by PMRT. The purpose of this study was to evaluate and compare clinical characteristics and survival outcomes between patients with $\mathrm{LABC}$ who received mastectomy alone or IBR in a single institution.

\section{METHODS}

We obtained data from the Seoul National University Hospital Database. The analysis included cases diagnosed with clinical stage III or pathological stage III breast cancer and underwent curative operation between January 2004 and December 2015. The patients who underwent total mastectomy, radical mastectomy, modified radical mastectomy, skin sparing mastectomy, or nipple-areolar-complex sparing mastectomy were included. We identified 77 and 171 patients with or without IBR, respectively. All the patients were over 18 years old when they were diagnosed. All patients with a follow-up length less than 12 months, or inadequate amount of data were excluded. The following data collected: BMI, age-at-diagnosis, histologic type and grade, hormone receptor status, human epidermal growth factor receptor-2 (HER2) status, clinical or pathologic stage, modality of adjuvant treatment, endocrine therapy, monoclonal antibody therapy, time to adjuvant chemotherapy, fertility preservation, type of reconstruction and DFS. The breast cancer was pathologically staged according to 7 th AJCC criteria. We reviewed the electronic medical records of the patients to identify the occurrence of loco-regional recurrence or distant metastasis and type of reconstructive materials. This study was conducted with the approval of the Institutional Review Board of Seoul National University Hospital (IRB No. H-1812-066-993).

At present, many patients have already been terminated, died, or have been transferred to other hospitals. Patients who are still being treated at our hospital have a follow-up period of more than 6 months, so it is not practical to obtain individual consent for a large number of patients. Since this study is a retrospective cohort study through retrospective medical records review, there is no additional harm to patients except the exposure of personal medical records information. In this respect, we were granted a waiver of consent.

We defined loco-regional recurrence as the recurrence on remnant skin, ipsilateral chest wall or ipsilateral regional lymph nodes. Distant recurrence was defined as recurrence at any distant organ or lymph nodes except ipsilateral axilla and cervical area. DFS was defined as the length of time after surgery for primary breast cancer to the earliest report of any loco-regional or distant recurrence

\section{Statistical analysis}

We used the Mann-Whitney U test for comparing clinical-pathologic features. Survival outcome was estimated by the Kaplan-Meier method. We used 'R' for statistical analysis (R version 3.5). Two-sided $p$ value less than 0.05 was considered statistically significant.

\section{RESULTS}

\section{Patients and tumor characteristics}

Among 248 patients who were enrolled in this study, 77 women underwent breast reconstruction at the time of mastectomy and the other 171 had mastectomy performed without reconstruction. The clinical and pathologic information of the two groups are listed in Table 1. Median follow-up time was 49 months and the mean age of patients was 49 (range 28-84) years in this study population. The patients with IBR were significantly younger than women that received MA (43 vs. 55, $p<0.001$ ) and no patient older than 55 years underwent IBR in our cohort. BMI of the patients with IBR was lower than that of patients who had MA performed (22.2 vs. 23.4, $p=0.001$ ). The IBR group had a higher rate of being progesterone receptor-positive, but there was no difference between the two groups regarding endocrine therapy was required (Table 1 ).

\section{Treatment modality}

The patients in both groups were treated by neo- and adjuvant chemotherapy, endocrine therapy and/or radiotherapy in accordance with standard protocol. Briefly, 242 (97.6\%) patients were treated with chemotherapy; the remaining 6 patients did not receive chemotherapy due to old age and/or poor general condition. While one-third of the patients with IBR received preoperative chemotherapy, over twothirds of patients in the MA group were treated with preoperative chemotherapy (36.4\% vs. $69.6 \%, p<0.001)$. The difference in rate of neoadjuvant chemotherapy was statistically significant between the two groups, but the response status after neoadjuvant chemotherapy was not significantly different between the two groups (Table 2). Over 90\% of all patients received PMRT according to treatment guidelines. 
Table 1. Demographic and clinical information of the study subject

\begin{tabular}{|c|c|c|c|}
\hline Variable & $\begin{array}{l}\text { IBR group } \\
(\mathrm{n}=77) \\
\text { No. }(\%)\end{array}$ & $\begin{array}{c}\text { MA group } \\
(n=171) \\
\text { No. }(\%)\end{array}$ & $p$-value \\
\hline Body mass index $\left(\mathrm{kg} / \mathrm{m}^{2}\right)^{*}$ & $22.2[20.8-23.9]$ & $23.4[21.6-25.9]$ & 0.001 \\
\hline Age $^{*}$ & $43.0[36.0-47.0]$ & $55.0[48.0-61.0]$ & $<0.001$ \\
\hline Histologic type & & & 0.531 \\
\hline Ductal carcinoma & $64(83.1)$ & $152(88.9)$ & \\
\hline Lobular carcinoma & $6(7.8)$ & $10(5.8)$ & \\
\hline Others & $7(8.1)$ & $9(5.2)$ & \\
\hline AJCC stage (7th edition) & & & 0.239 \\
\hline IIIA & $49(63.6)$ & $105(61.4)$ & \\
\hline IIIIB & $9(11.7)$ & $11(6.4)$ & \\
\hline IIIC & $19(24.7)$ & $55(32.2)$ & \\
\hline T stage & & & 0.401 \\
\hline 1 & $9(11.7)$ & $17(9.9)$ & \\
\hline 2 & $33(42.9)$ & $83(48.5)$ & \\
\hline 3 & $28(36.4)$ & $47(27.5)$ & \\
\hline 4 & $7(9.1)$ & $24(14.0)$ & \\
\hline N stage & & & 0.484 \\
\hline 0 & $1(1.3)$ & $2(1.2)$ & \\
\hline 1 & $17(22.1)$ & $26(15.2)$ & \\
\hline 2 & $40(51.9)$ & $88(51.5)$ & \\
\hline 3 & $19(24.7)$ & $55(32.2)$ & \\
\hline Nottingham Histologic Score & & & 0.738 \\
\hline I & $2(2.6)$ & $6(3.5)$ & \\
\hline ॥ & $37(48.1)$ & $73(42.7)$ & \\
\hline III & $38(49.4)$ & $92(53.8)$ & \\
\hline ER & & & 0.082 \\
\hline Positive & $57(74.0)$ & $108(63.2)$ & \\
\hline Negative & $20(26.0)$ & $63(36.8)$ & \\
\hline PR & & & 0.004 \\
\hline Positive & $43(55.8)$ & $63(36.8)$ & \\
\hline Negative & $34(44.2)$ & $108(63.2)$ & \\
\hline HER2 & & & 1.000 \\
\hline Positive & $16(20.8)$ & $48(28.1)$ & \\
\hline Negative & 61 (79.2) & $123(71.9)$ & \\
\hline
\end{tabular}

(Continued to the next)

In 92 patients who were received adjuvant chemotherapy, the time to initiation of chemotherapy after surgery was not different between IBR and MA groups $(34.5 \pm 26.6$ vs. $31.4 \pm 10.5, p=0.470)$ (Table 1$)$. When comparing the IBR group and MA group, there was no statistically significant difference in the rate of endocrine therapy with Estrogen receptor (ER) or Progesterone receptor (PR) positive $(98.3 \%$ vs. $95.5 \%, p=0.624$ ) (Table 1). Similarly, there was no statistically significant difference between the two groups in using Trastuzumab with HER2 positive (95.5\% vs. 95.8\%, $p=1.000$ ) (Table 1). The percentage of fertility preservation in the IBR group was significantly higher than
Table 1. Continued

\begin{tabular}{|c|c|c|c|}
\hline Variable & $\begin{array}{l}\text { IBR group } \\
(n=77) \\
\text { No. }(\%)\end{array}$ & $\begin{array}{c}\text { MA group } \\
(n=171) \\
\text { №. }(\%)\end{array}$ & $p$-value \\
\hline \multicolumn{4}{|l|}{ Chemotherapy } \\
\hline Yes & $76(98.7)$ & $166(97.1)$ & 0.746 \\
\hline No & $1(1.3)$ & $5(2.9)$ & \\
\hline Chemotherapy-detailed & & & $<0.001$ \\
\hline Neoadjuvant & $28(36.4)$ & $119(69.6)$ & \\
\hline Adjuvant & $46(59.7)$ & $46(28.7)$ & \\
\hline Unknown & $2(2.6)$ & $1(0.6)$ & \\
\hline No & $1(1.3)$ & $5(2.9)$ & \\
\hline Time to adjuvant chemotherapy & $34.5 \pm 26.6$ & $31.4 \pm 10.5$ & 0.470 \\
\hline Endocrine therapy, ER or PR (+) & 58 & 111 & 0.624 \\
\hline Yes & $57(98.3)$ & $106(95.5)$ & \\
\hline No & $1(1.7)$ & $5(4.5)$ & \\
\hline Trastuzumab, HER2 (+) & 22 & 48 & 1.000 \\
\hline Yes & $21(95.5)$ & $46(95.8)$ & \\
\hline No & $1(4.5)$ & $2(4.2)$ & \\
\hline Fertility preservation, goserelin & & & $<0.001$ \\
\hline Yes & $15(19.5)$ & $7(4.1)$ & \\
\hline No & $62(80.5)$ & $164(95.9)$ & \\
\hline Radiotherapy & & & 0.743 \\
\hline Yes & $69(89.6)$ & $149(87.1)$ & \\
\hline No & $8(10.4)$ & $22(12.9)$ & \\
\hline \multicolumn{4}{|l|}{ Type of reconstruction } \\
\hline $\begin{array}{l}\text { Implant (including tissue } \\
\text { expander) }\end{array}$ & 24 & $\mathrm{~N} / \mathrm{A}$ & \\
\hline Autologous tissue & 53 & $\mathrm{~N} / \mathrm{A}$ & \\
\hline
\end{tabular}

$\mathrm{IBR}=$ immediate breast reconstruction; $\mathrm{MA}=$ mastectomy alone; $\mathrm{ER}=$ estrogen receptor; $\mathrm{PR}=$ progesterone receptor; $\mathrm{HER} 2$ = human epidermal growth factor receptor-2; $\mathrm{T}$ stage $=$ tumor stage; $\mathrm{N}$ stage $=$ node stage; $\mathrm{N} / \mathrm{A}$ : not applicable.

${ }^{*}$ Mean [range].

Table 2. Response status after neoadjuvant chemotherapy

\begin{tabular}{lccc}
\hline Response & $\begin{array}{c}\text { IBR } \\
(\mathrm{n}=28) \\
\text { No. (\%) }\end{array}$ & $\begin{array}{c}\text { MA } \\
(\mathrm{n}=119) \\
\text { No. }(\%)\end{array}$ & $p$-value \\
\hline Response status & & & 0.615 \\
Partial response & $24(85.7)$ & $93(78.2)$ & \\
Stable disease & $3(10.7)$ & $22(18.5)$ & \\
Disease progression & $1(3.6)$ & $4(3.4)$ & \\
\hline
\end{tabular}

$\mathrm{IBR}=$ immediate breast reconstruction; $\mathrm{MA}=$ mastectomy alone.

that in the MA group (Table 1).

According to the modality of immediate breast reconstruction, the recurrence rate, loco-regional recurrence rate, and distant recurrence rate did not show statistically significant difference. Autologous tissue group showed longer DFS than the implant group ( 90.5 vs. 57.8 , $p=0.021)($ Table 3$)$. 
Table 3. Recurrence rate and DFS in two different reconstruction modalities

\begin{tabular}{lccc}
\hline Recurrence/DFS & $\begin{array}{c}\text { Autologous tissue } \\
(\mathrm{n}=53) \\
\text { No. }(\%)\end{array}$ & $\begin{array}{c}\text { Implant } \\
(\mathrm{n}=24) \\
\text { No. }(\%)\end{array}$ & $p$-value \\
\hline $\begin{array}{l}\text { Recurrence } \\
\text { Yes }\end{array}$ & $9(17.0)$ & $8(33.3)$ & 0.192 \\
No & $44(83.0)$ & $16(66.7)$ & \\
Locoregional & & & 0.175 \\
Yes & 0 & $2(8.3)$ & \\
No & $53(100)$ & $22(91.7)$ & \\
Distant & & & 0.608 \\
Yes & $9(17.0)$ & $6(25.0)$ & \\
No & $44(83.0)$ & $18(75.0)$ & \\
DFS (mo) & $90.5[61.9-125.8]$ & $57.8[37.0-97.0]$ & 0.021 \\
\hline
\end{tabular}

DFS = disease free survival.

*Mean [range].

Table 4. Recurrence rate and DFS in IBR group and MA group

\begin{tabular}{lccc}
\hline Recurrence/DFS & $\begin{array}{c}\text { IBR } \\
(\mathrm{n}=77) \\
\text { No. }(\%)\end{array}$ & $\begin{array}{c}\text { MA } \\
(\mathrm{n}=171) \\
\text { No. }(\%)\end{array}$ & $p$-value \\
\hline $\begin{array}{l}\text { Recurrence } \\
\text { Yes }\end{array}$ & $17(22.1)$ & $53(31.0)$ & 0.197 \\
$\quad$ No & $60(77.9)$ & $118(69.0)$ & \\
Locoregional recurrence & & & 0.079 \\
Yes & $2(2.6)$ & $17(9.9)$ & \\
No & $75(97.4)$ & $154(90.1)$ & \\
Distant recurrence & & & 0.200 \\
Yes & $15(19.5)$ & $48(28.1)$ & \\
No & $62(80.5)$ & $123(71.9)$ & \\
DFS (mo)* & $81.3[52.0-120.7]$ & $49.8[39.8-56.8]$ & $<0.001$
\end{tabular}

$\mathrm{IBR}=$ immediate breast reconstruction; $\mathrm{MA}=$ mastectomy alone; $\mathrm{DFS}=$ disease free survival.

*Mean [range].

\section{Recurrence \& Disease-free survival}

A total of 70 (28.2\%) patients experienced recurrence by the follow-up date. The recurrence rate was not different between the IBR and MA group (22.1\% and 31.0\%, respectively, $p=0.197)$. There were $17(9.9 \%)$ cases of loco-regional recurrence in the patients who received MA, in contrast with two of 77 (2.6\%) women who had IBR performed $(p=0.079)$. Distant metastasis was found in $15(19.5 \%)$ and 48 (28.1\%) patients with or without IBR, respectively $(p=0.200)$. The median DFS for women with IBR was 81.3 months, whereas for patients with MA it was 49.8 months $(p<0.001)$ (Table 4$)$. In a subset analysis according to stage stratification, the women who received IBR showed better DFS than those who underwent MA in both stage IIIA and, IIIB/IIIC $(p<0.001)$. In all subtypes regarding ER and
Table 5. Univariate (chi-square) and multivariate (Cox regression) analysis for clinical-pathologic features associated with disease-free survival in study subjects

\begin{tabular}{|c|c|c|c|c|}
\hline \multirow{2}{*}{$\begin{array}{l}\text { Variable (reference vs. } \\
\text { comparison target) }\end{array}$} & \multirow{2}{*}{$\begin{array}{c}\text { Univariate } \\
\text { analysis } \\
p \text {-value }\end{array}$} & \multicolumn{3}{|c|}{ Multivariate analysis } \\
\hline & & $\begin{array}{l}\text { Hazard } \\
\text { ratio }\end{array}$ & $\begin{array}{c}95 \% \\
\text { Confidence } \\
\text { interval }\end{array}$ & $p$-value \\
\hline MA vs IBR & 0.013 & 0.37 & {$[0.20,0.69]$} & 0.002 \\
\hline BMI ( <23 vs. $\geq 23$ ) & 0.029 & 0.64 & {$[0.39,1.05]$} & 0.077 \\
\hline $\begin{array}{l}\text { Age (at diagnosis, } \\
<48 \text { vs. } \geq 48 \text { ) }\end{array}$ & 0.370 & & & \\
\hline $\begin{array}{l}\text { Histologic grade (Low vs. } \\
\text { High) }\end{array}$ & 0.002 & 1.94 & {$[1.16,3.25]$} & 0.011 \\
\hline $\begin{array}{l}\text { Estrogen receptor } \\
\text { (positive vs. negative) }\end{array}$ & 0.015 & 0.81 & {$[0.48,1.35]$} & 0.408 \\
\hline Stage (IIIA vs. IIIB/IIIC) & $<0.001$ & 2.31 & {$[1.21,4.42]$} & 0.012 \\
\hline $\begin{array}{l}\text { Fertility preservation } \\
\text { (no vs. goserelin ) }\end{array}$ & 0.054 & 2.03 & {$[0.99,4.16]$} & 0.053 \\
\hline
\end{tabular}

$\mathrm{MA}=$ mastectomy alone; $\mathrm{IBR}=$ immediate breast reconstruction; $\mathrm{BMI}=$ body mass index.

HER2 status, IBR patients were not inferior to MA patients in DFS (Figure 1).

In multivariate analysis adjusting for BMI, age-at-diagnosis, histologic grade, ER, stage, and fertility preservation, mastectomy-alone, histologic grade, and stage showed higher Hazard ratio (HR). IBR group showed significantly better DFS than MA group (HR for recurrence; $0.37,95 \%$ CI $0.20-0.69, p=0.002$ ) (Table 5).

\section{DISCUSSION}

When a mastectomy is mandatory due to breast cancer, recent treatment guidelines recommend that the surgeon should determine the type of operation depending on the patient's personal preferences and the surgeon's experience. However, it should be noted that IBR does not result in delaying appropriate surgical intervention, nor does it compromise oncological safety. In patients with advanced stage disease, there is typically more concern about the safety of IBR, but there is limited evidence to support this. Furthermore, there are conflicting results with regards to treatment delay or complication rate in LABC patients who received IBR. The present study showed that IBR in patients with stage III disease did not impair oncological outcomes, which is consistent with the findings of previous studies [17-20].

Today, with advances in multi-modality approaches that can im- 

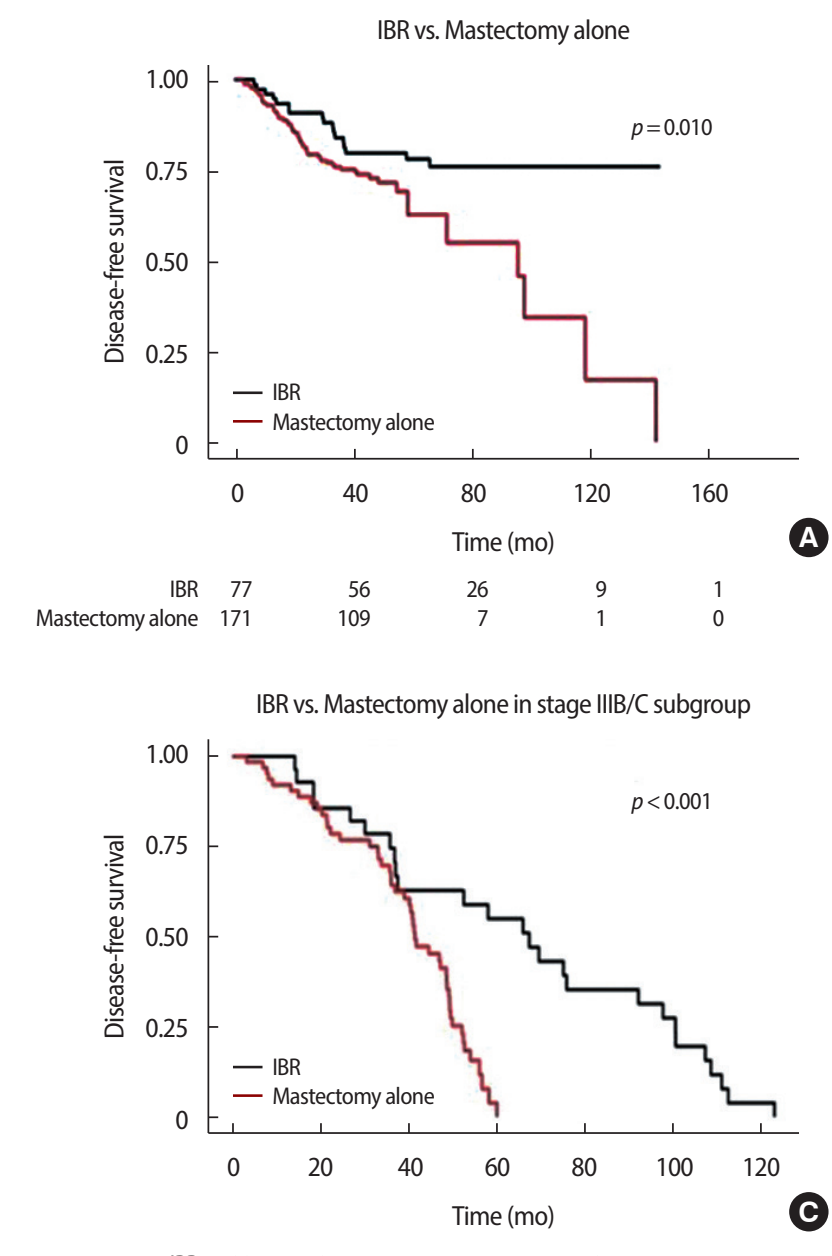

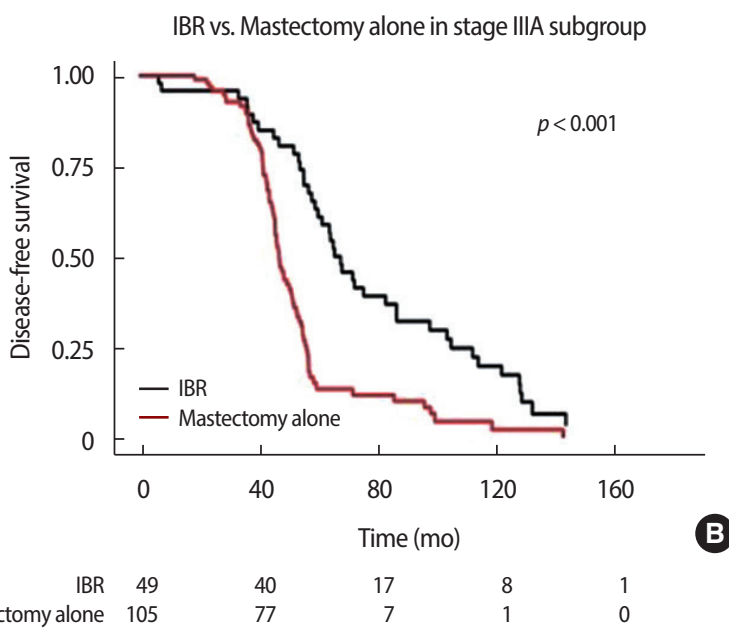

IBR vs. Mastectomy alone in ER positive/Her-2 negative subgroup

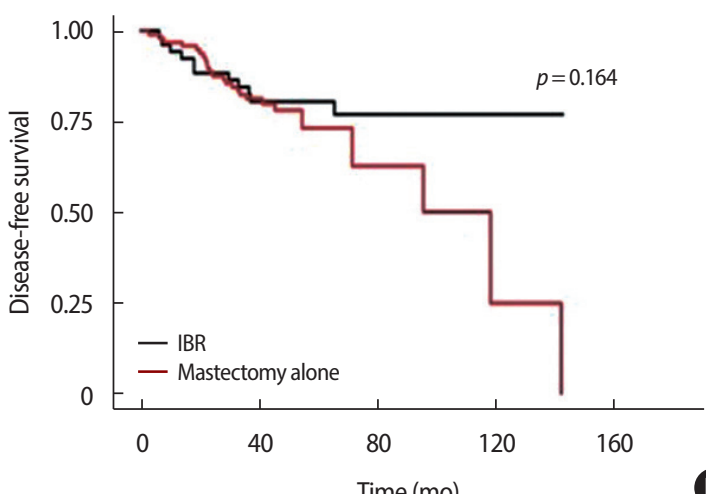

$\begin{array}{rrrrrr}\text { IBR } & 53 & 39 & 17 & 6 & 1 \\ \text { Mastectomy alone } & 98 & 65 & 6 & 1 & 0\end{array}$

IBR vs. Mastectomy alone in triple negative breast cancer subgroup

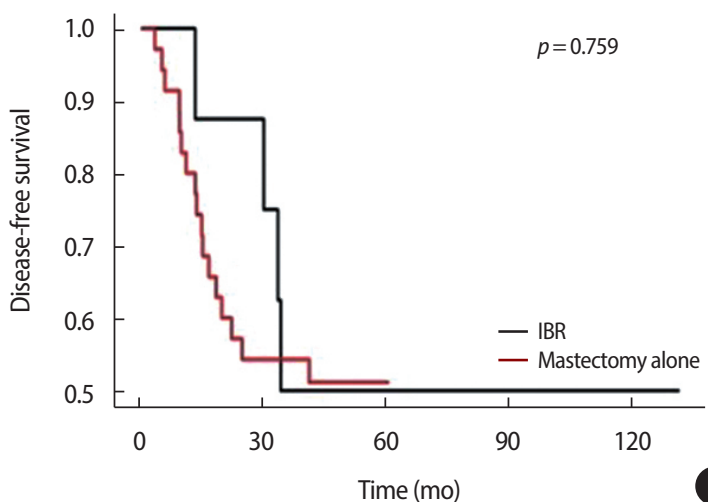

$\begin{array}{rrrrrr}\text { IBR } & 8 & 6 & 3 & 2 & 1 \\ \text { Mastectomy alone } & 35 & 19 & 0 & 0 & 0\end{array}$

$\begin{array}{rrrrrr}\text { IBR } & 12 & 11 & 10 & 6 & 2 \\ \text { Mastectomy alone } & 24 & 18 & 1 & 1 & 0\end{array}$

E

Figure 1. The effects of clinical-pathologic variables on the disease-free survival (DFS). The Kaplan-Meier survival curves for DFS according to IBR, stage subgroups and tumor characteristics.

prove the outcome of LABC [21-23], better quality of life can be achieved with IBR. This is extremely significant for survivors of breast

cancer. Also, the increasing trend of using preoperative chemotherapy rather than postoperative chemotherapy for LABC has substantially 
reduced the concern of chemotherapy delay due to IBR [24-27]. Although the primary goal of preoperative chemotherapy is breast conservation, total mastectomy is still unavoidable when the tumor size is not reduced enough for conserving surgery, or due to the patients choice for mastectomy despite the fact that breast conservation is feasible.

There have been concerns of delay or interference with postoperative chemotherapy or post-mastectomy radiotherapy due to IBR. Our study demonstrated that there was no delay of postoperative chemotherapy in the 92 patients who eventually received it (Table 1). This is consistent with previous studies that investigated delays in adjuvant therapy due to IBR $[28,29]$. Frasier et al showed that recently increased use of PMRT in LABC was not associated with a decrease in IBR rate [30].

The results obtained of improved DFS in the IBR group compared with the MA group (HR 0.37, 95\% CI 0.20-0.69, $p=0.002$ ) is consistent with previous studies that showed better survival outcome in patients who received reconstructions [31]. Bezuhly et al. [32] concluded that IBR is associated with decreased mortality among younger women in an analysis of US SEER data. Similarly, Hsieh [31] demonstrated that immediate TRAM flap reconstruction might be an independent predictor of favorable survival outcome. These results, including the present study, might be due to a selection bias, despite adjustment of known prognostic factors. There was no statistically significant difference in recurrence rate between the two groups that underwent autologous tissue vs. implant, but there was a statistically significant difference in DFS. A total of 24 subjects in the implant group was considered to be too small for statistical analysis (Table 3). This is an intrinsic limitation of the retrospective analysis. Also, previous reports suggested that the patients with higher socio-economic status were more likely to choose reconstruction [33-36], which can be a potentially favorable prognostic factor. Therefore, careful interpretation of these retrospective studies is needed. In any case, our results suggest that IBR did not have a negative effect on LABC patients' long term survival.

Many possible variables were considered in the statistical analysis. The variables found to be statistically significant include BMI, age-at-diagnosis, PR status, chemotherapy-detailed, and fertility preservation. However, the difference of response status of neoadjuvant chemotherapy in the IBR group vs. MA group was not statistically significant. If ER or PR was positive, there was no statistically significant difference in endocrine therapy. Therefore, only BMI, age-at-diagnosis and fertility preservation were the non-stratification variables when comparing the two groups. We performed univariate analysis and multivariate analysis between the two groups. The results were that IBR, histologic grade and stage had a statistically significant effect on hazard ratio (Table 5).

Some weaknesses of the present study include modest length of follow-up (49 months), relatively small number of patients with low statistical power, no information on postoperative complication rate, and lack of data about morbidity or underlying medical/socio-economic status in both groups.

In conclusion, we demonstrated that IBR for LABC patients did not impair their disease-free survival outcome during an average of 49 months compared with mastectomy alone without reconstruction. In the absence of prospective study evidence, our results based on retrospective data can help surgeons choose immediate reconstruction as an option for patients with LABC.

\section{REFERENCES}

1. Yang RL, Newman AS, Lin IC, Reinke CE, Karakousis GC, Czerniecki BJ, et al. Trends in immediate breast reconstruction across insurance groups after enactment of breast cancer legislation. Cancer 2013;119:2462-8.

2. Reuben BC, Manwaring J, Neumayer LA. Recent trends and predictors in immediate breast reconstruction after mastectomy in the United States. Am J Surg 2009;198:237-43.

3. Sisco M, Du H, Warner JP, Howard MA, Winchester DP, Yao K. Have we expanded the equitable delivery of postmastectomy breast reconstruction in the new millennium? Evidence from the national cancer data base. J Am Coll Surg 2012;215:658-66.

4. Polednak AP. How frequent is postmastectomy breast reconstructive surgery? A study linking two statewide databases. Plast Reconstr Surg 2001;108:73-7.

5. Gieni M, Avram R, Dickson L, Farrokhyar F, Lovrics P, Faidi S, et al. Local breast cancer recurrence after mastectomy and immediate breast reconstruction for invasive cancer: A meta-analysis. Breast 2012;21:230-6.

6. Zhang P, Li CZ, Wu CT, Jiao GM, Yan F, Zhu HC, et al. Comparison 
of immediate breast reconstruction after mastectomy and mastectomy alone for breast cancer: A meta-analysis. Eur J Surg Oncol 2017;43:285-93.

7. Sandelin K, Wickman M, Billgren AM. Oncological outcome after immediate breast reconstruction for invasive breast cancer: a longterm study. Breast 2004;13:210-8.

8. Noone RB, Frazier TG, Noone GC, Blanchet NP, Murphy JB, Rose D. Recurrence of breast carcinoma following immediate reconstruction: a 13-year review. Plast Reconstr Surg 1994;93:96-106.

9. Slavin SA, Schnitt SJ, Duda RB, Houlihan MJ, Koufman CN, Morris DJ, et al. Skin-sparing mastectomy and immediate reconstruction: oncologic risks and aesthetic results in patients with early-stage breast cancer. Plast Reconstr Surg 1998;102:49-62.

10. Colleoni M, Bonetti M, Coates AS, Castiglione-Gertsch M, Gelber RD, Price K, et al. Early start of adjuvant chemotherapy may improve treatment outcome for premenopausal breast cancer patients with tumors not expressing estrogen receptors. The International Breast Cancer Study Group. J Clin Oncol 2000;18:584-90.

11. Contant CM, van Geel AN, van der Holt B, Griep C, Tjong Joe Wai R, Wiggers T. Morbidity of immediate breast reconstruction (IBR) after mastectomy by a subpectorally placed silicone prosthesis: the adverse effect of radiotherapy. Eur J Surg Oncol 2000;26:344-50.

12. Vandeweyer E, Deraemaecker R, Nogaret JM, Hertens D. Immediate breast reconstruction with implants and adjuvant chemotherapy: a good option? Acta Chir Belg 2003;103:98-101.

13. Yule GJ, Concannon MJ, Croll G, Puckett CL. Is there liability with chemotherapy following immediate breast construction? Plast Reconstr Surg 1996;97:969-73.

14. Kontos M, Lewis RS, Luchtenborg M, Holmberg L, Hamed H. Does immediate breast reconstruction using free flaps lead to delay in the administration of adjuvant chemotherapy for breast cancer? Eur J Surg Oncol 2010;36:745-9.

15. Cho EH, Shammas RL, Phillips BT, Greenup RA, Hwang ES, Hollenbeck ST. Breast cancer after augmentation: oncologic and reconstructive considerations among women undergoing mastectomy. Plast Reconstr Surg 2017;139:1240e-9e.

16. Warren Peled A, Itakura K, Foster RD, Hamolsky D, Tanaka J, Ewing $\mathrm{C}$, et al. Impact of chemotherapy on postoperative complications after mastectomy and immediate breast reconstruction. Arch Surg 2010;145:880-5.
17. Aurilio G, Bagnardi V, Graffeo R, Nole F, Petit JY, Locatelli M, et al. Does immediate breast reconstruction after mastectomy and neoadjuvant chemotherapy influence the outcome of patients with non-endocrine responsive breast cancer? Anticancer Res 2014;34: 6677-83.

18. Lee TJ, Hur WJ, Kim EK, Ahn SH. Outcome of management of local recurrence after immediate transverse rectus abdominis myocutaneous flap breast reconstruction. Arch Plast Surg 2012;39:376-83.

19. Ota D, Fukuuchi A, Iwahira Y, Kato T, Takeuchi M, Okamoto J, et al. Clinical outcome of reconstruction with tissue expanders for patients with breast cancer and mastectomy. Clin Breast Cancer 2014; 14:339-45.

20. Aurilio G, Bagnardi V, Nole F, Pruneri G, Graffeo R, Petit JY, et al. Outcome of immediate breast reconstruction in patients with nonendocrine-responsive breast cancer: A monoinstitutional case-control study. Clin Breast Cancer 2015;15:e237-41.

21. Dawood S, Ueno NT, Valero V, Woodward WA, Buchholz TA, Hortobagyi GN, et al. Differences in survival among women with stage III inflammatory and noninflammatory locally advanced breast cancer appear early: a large population-based study. Cancer 2011;117:1819-26.

22. Schroeder MC, Rastogi P, Geyer CE, Jr., Miller LD, Thomas A. Early and locally advanced metaplastic breast cancer: presentation and survival by receptor status in surveillance, epidemiology, and end results (SEER) 2010-2014. Oncologist 2018;23:481-8.

23. Masuda H, Brewer TM, Liu DD, Iwamoto T, Shen Y, Hsu L, et al. Long-term treatment efficacy in primary inflammatory breast cancer by hormonal receptor- and HER2-defined subtypes. Ann Oncol 2013;25:384-91.

24. Cordeiro PG, Albornoz CR, McCormick B, Hu Q, Van Zee K. The impact of postmastectomy radiotherapy on two-stage implant breast reconstruction: an analysis of long-term surgical outcomes, aesthetic results, and satisfaction over 13 years. Plast Reconstr Surg 2014;134:588-95.

25. Early Breast Cancer Trialists' Collaborative G. Long-term outcomes for neoadjuvant versus adjuvant chemotherapy in early breast cancer: meta-analysis of individual patient data from ten randomised trials. Lancet Oncol 2018;19:27-39.

26. Kuerer HM. Increasing breast cancer systemic therapy use before surgery in the United States: scaling down and the promise of selec- 
tive elimination of surgery. Ann Surg Oncol 2018;25:3115-8.

27. Nava MB, Pennati AE, Lozza L, Spano A, Zambetti M, Catanuto G.

Outcome of different timings of radiotherapy in implant-based breast reconstructions. Plast Reconstr Surg 2011;128:353-9.

28. Ng YY, Tan VK, Goh TL, Yong WS, Wong CY, Ho GH, et al. Trends in post-mastectomy reconstruction in an asian population: A 12year institutional review. Breast J 2017;23:59-66.

29. Paillocher N, Florczak AS, Richard M, Classe JM, Oger AS, Raro P, et al. Evaluation of mastectomy with immediate autologous latissimus dorsi breast reconstruction following neoadjuvant chemotherapy and radiation therapy: A single institution study of 111 cases of invasive breast carcinoma. Eur J Surg Oncol 2016;42:949-55.

30. Frasier LL, Holden S, Holden T, Schumacher JR, Leverson G, Anderson B, et al. Temporal trends in postmastectomy radiation therapy and breast reconstruction associated with changes in national comprehensive cancer network guidelines. JAMA Oncol 2016;2:95101.

31. Hsieh TY, Lin YN, Lin SD, Lai CS, Chang KP, Lee SS, et al. Immediate transverse rectus abdominis musculocutaneous flap reconstruction is associated with improved cancer-specific survival in locally advanced breast cancer. Ann Plast Surg 2014;73 Suppl 1:S31-6.

32. Bezuhly M, Temple C, Sigurdson LJ, Davis RB, Flowerdew G, Cook $\mathrm{EF}$, Jr. Immediate postmastectomy reconstruction is associated with improved breast cancer-specific survival: evidence and new challenges from the Surveillance, Epidemiology, and End Results database. Cancer 2009;115:4648-54.

33. Gordon NH, Crowe JP, Brumberg DJ, Berger NA. Socioeconomic factors and race in breast cancer recurrence and survival. Am J Epidemiol 1992;135:609-18.

34. Morrow M, Scott SK, Menck HR, Mustoe TA, Winchester DP. Factors influencing the use of breast reconstruction postmastectomy: a National Cancer Database study. J Am Coll Surg 2001;192:1-8.

35. Alderman AK, Hawley ST, Waljee J, Mujahid M, Morrow M, Katz SJ. Understanding the impact of breast reconstruction on the surgical decision-making process for breast cancer. Cancer 2008;112:48994.

36. Sabatino SA, Coates RJ, Uhler RJ, Breen N, Tangka F, Shaw KM. Disparities in mammography use among US women aged 40-64 years, by race, ethnicity, income, and health insurance status, 1993 and 2005. Med Care 2008;46:692-700. 